\title{
Pengujian Black Box pada Aplikasi Penjualan Berbasis Web Menggunakan Teknik Boundary Value Analysis
}

\author{
Muhamad Nurudin ${ }^{1}$, Windi Jayanti ${ }^{2}$, Rio Dwi Saputro ${ }^{3}$, Masda Priadyan Saputra ${ }^{4}$, dan \\ Yulianti $^{5}$
}

Teknik Informatika, Universitas Pamulang, Tangerang Selatan, Banten, Indonesia, 15416 e-mail:1nurudin.abc@gmail.com, ${ }^{2}$ windijayanti95@gmail.com, ${ }^{3}$ rio06121998@gmail.com, 4priardyans@gmail.com, 5yulianti@unpam.ac.id

Submitted Date: December $23^{\text {rd }}, 2019$

Revised Date: December 29 $9^{\text {th }}, 2019$
Reviewed Date: December $28^{\text {th }}, 2019$

Accepted Date: January $9^{\text {th }}, 2020$

\begin{abstract}
In a software test, validation is one of the processes of checking whether the software meets the expected specifications and objectives or not. The data validation process has not been maximized can result in a mismatch of data that will be stored in the database. For example the amount of stock turned negative, or the number of digits entered can exceed the defined limits. This can be detrimental to the owner and user in using this application. Therefore, it is necessary to improve the quality of validation more accurately, so it can help the owner in terms of data accuracy. Applications are designed in such a way must go through a testing phase to ensure the quality of the software itself. Examples of tests can be said to be good if they have a chance of finding an error that cannot be revealed. Among the many ways of the Black Box testing methods, this study uses the Boundary Value Analysis testing method. The method tests the maximum number of limits and the minimum number of limits to produce a valid value, which is considered quite relevant for testing sales applications at PT Karunia Segar Kedua. The initial stage of the research needs to be done is to define the functionality to be tested, compile the test scheme, choose the material to be tested, determine the maximum and minimum number of limits in accordance with a predetermined database structure, conduct experiments, document research results, and draw conclusions. The conclusion is based on the testing has been done is software can be used properly, after an improvement is made on the errors found. However, this test has not been said to be perfect, because it is only done using a sample form. From the results of this test it is expected that the application can be used according to user requirements.
\end{abstract}

Keywords: Application Testing, Black Box, Sales System, Boundary Value Analysis

\begin{abstract}
Abstrak
Dalam sebuah pengujian perangkat lunak, validasi adalah salah satu proses pemeriksaan atau pengecekan apakah perangkat lunak memenuhi spesifikasi dan tujuan yang diharapkan atau tidak. Proses validasi data yang belum maksimal dapat mengakibatkan ketidaksesuaian data yang akan disimpan pada basis data. Contohnya jumlah stok berubah menjadi negatif, atau jumlah digit yang dimasukkan dapat melebihi batas yang didefinisikan. Hal ini dapat merugikan pemilik dan pengguna dalam menggunakan aplikasi ini. Oleh karena itu, diperlukan perbaikan kualitas validasi yang lebih akurat, sehingga dapat membantu pemilik dalam keakuratan data. Aplikasi yang dirancang sedemikian rupa harus melalui tahap pengujian untuk memastikan kualitas dari perangkat lunak itu sendiri. Contoh pengujian yang dapat dikatakan baik apabila mempunyai peluang menemukan sebuah error yang tidak dapat terungkap. Dari beberapa cara pengujian Black Box, penelitian kali ini menggunakan metode pengujian Boundary Value Analysis. Metode tersebut menguji jumlah limit maksimal dan jumlah limit minimal untuk menghasilkan nilai yang valid, yang dinilai cukup relevan untuk menguji aplikasi penjualan pada PT Karunia Segar Kedua. Tahap awal penelitian yang perlu dilakukan yaitu dengan mendefinisikan fungsionalitas yang akan diuji, menyusun skema pengujian, memilih bahan yang akan diuji, menentukan jumlah limit maksimal dan minimal sesuai dengan struktur basis data yang telah ditentukan, mengadakan eksperimen, dokumentasi hasil penelitian, dan penarikan kesimpulan. Kesimpulan yang dihasilkan berdasarkan pengujian yang telah
\end{abstract}


dilakukan yaitu perangkat lunak ini dapat digunakan dengan baik, setelah dilakukan perbaikan pada kesalahan yang ditemukan. Akan tetapi pengujian ini belum dikatakan sempurna, karena hanya dilakukan dengan menggunakan form sampel. Dari hasil pengujian ini diharapkan aplikasi dapat digunakan sesuai kebutuhan pengguna.

Kata kunci: Pengujian Sistem, Black Box, Sistem Penjualan, Boundary Value Analysis

\section{Pendahuluan}

Perkembangan website yang sangat pesat dalam beberapa tahun terakhir menimbulkan sejumlah dampak dalam aspek masyarakat, bisnis, pendidikan, pemerintahan, hiburan, industri, bahkan dalam aspek kehidupan pribadi. Keuntungan utama dalam mengadopsi web untuk pengembangan perangkat lunak di antaranya adalah minimnya biaya instalasi, peningkatan fitur baru untuk pengguna secara otomatis, dan akses secara menyeluruh dari semua perangkat yang terhubung dengan internet. Untuk itu kualitas suatu aplikasi berbasis web sangat diperlukan untuk menunjang aplikasi itu sendiri.

Salah satu aplikasi berbasis web yaitu aplikasi penjualan pada PT Karunia Segar Kedua yang dirancang menggunakan bahasa pemrograman PHP dan MySQL sebagai tempat penyimpanan basis data. Aplikasi tersebut memungkinkan pengguna dapat melakukan transaksi penjualan, transaksi pembelian, memantau stok, dan menarik laporan. Tiap pengguna diberikan hak akses tertentu sesuai fungsi dan tangung jawab masing-masing, sehingga Kasir dan Manager akan mengakses aplikasi dari sisi yang berbeda.

Menurut Oscar dalam (MZ, 2016), pengujian aplikasi bertujuan untuk memperoleh produk yang berkualitas yang memberikan produktivitas tinggi. Di mana kualitas aplikasi itu sendiri bergantung kepada kepuasan pelanggan atau pengguna (Cholifah, Yulianingsih, \& Sagita, 2018). Untuk itu, sebelum aplikasi diterapkan pada PT Karunia Segar Kedua, dilakukan pengecekan terlebih dahulu secara menyeluruh oleh pengguna, pengembang, dan penguji aplikasi. Pada pengujian tersebut ditemukan kesalahan ketika proses verifikasi data yang akan dimasukan, sehingga membuat data yang diharapkan tidak sesuai dengan data yang tersimpan pada basis data.

Dengan ditemukan adanya sebuah permasalahan, maka dapat disimpulkan bahwa masalah yang di hadapi oleh PT Karunia Segar Kedua yaitu bagaimana cara agar data yang dimasukkan ke dalam aplikasi lebih akurat dan sesuai dengan tipe data maupun batas yang didefinisikan. Sebagai contoh pada field stok, hanya bisa diisi karakter angka dengan batas 3 digit. Dengan metode Black Box Boundary Value Anaysis maka data akan diuji berdasarkan jumlah limit maksimal dan jumlah limit minimal agar menghasilkan nilai yang valid.

Aplikasi penjualan PT Karunia Segar Kedua memiliki beberapa menu yang memiliki fungsi yang berbeda. Namun pada pengujian saat ini dipilih sampel pada Form Tambah Barang, dikarenakan memiliki komponen form yang cukup lengkap dan dapat untuk mewakili formform yang lainnya.

\section{Metodologi}

Pentingnya pengujian aplikasi sangat diperlukan dalam penilaian kualitas aplikasi yang ada, agar fungsi dalam aplikasi dapat bekerja sesuai dengan yang diharapkan pengguna (Hidayat \& Putri, 2019). Kesalahan atau kekurangan dapat terdeteksi dari awal secara cepat apabila pengembang atau penguji perangkat lunak menyediakan tahap khusus untuk menguji program yang sudah dibuat kemudian dapat dikoreksi secepatnya (Mustaqbal, Firdaus, \& Rahmad, 2015).

Proses rekayasa perangkat lunak engineering harus dilakukan pada saat pengujian perangkat lunak. Referensi yang diusulkan dalam beberapa tahapan pengujian software dengan menyiapkan template untuk pengujian bagi pembuat perangkat lunak. Menurut Bhat dkk dalam (Hidayat \& Muttaqin, 2018), spesifikasi yang harus ada dalam pengujian berupa:

a. Pada sistem berbasis komputer, pengujian dimulai pada level modul dan bekerja keluar ke arah integrasi.

b. Poin yang berbeda sesuai dengan teknik pengujian yang berbeda pula.

c. Proyek yang besar harus dilakukan pengujian oleh pembuat/pengembang perangkat lunak yang bebas/independen.

d. Debugging harus diakomodasikan pada setiap tahap pengujian.

Langkah-langkah dalam pengujian software antara lain (Sutanto, Utomo, \& Perbawa, 2018):

- Unit testing, merupakan suatu aktifitas 
mencoba alur proses aplikasi pada struktur kontrol untuk memastikan fungsionalitas secara lengkap dan memaksimalkan pendeteksian kesalahan.

- Integration testing, merupakan sekumpulan dari permasalahan yang ditemukan pada verifikasi dan konstruksi program.

- High-order test yaitu aplikasi yang telah selesai akan diintegrasikan atau dirancang menjadi bagian yang lengkap dan menjadi satu kesatuan.

- Validation test, yaitu memberikan jaminan akhir bahwa aplikasi yang dirancang telah memenuhi semua kriteria yang diperlukan.

Salah satu metode pengujian yang berfokus pada spesifikasi fungsionalitas dari perangkat lunak disebut Black Box Testing (Vikasari, 2018). Pengujian ini memberikan gambaran atas sekumpulan kondisi masukan dan melakukan pengujian pada uraian fungsional program. Untuk menguji kesalahan yang tidak dapat dicakup oleh White Box Testing, maka solusi lainnya dapat menggunakan Black Box Testing. Menurut (Mustaqbal, Firdaus, \& Rahmad, 2015) Black Box Testing digunakan untuk mendeteksi permasalahan berikut:

a. Fungsi yang salah atau hilang.

b. Kesalahan pada interface.

c. Kesalahan struktur data dan basis data.

d. Kesalahan fungsi.

e. Kesalahan deklarasi dan terminasi.

Pengujian Black Box memiliki beberapa teknik, diantaranya Equivalence Partitioning, Boundary Value Analysis, Robustness Testing, Behavior Testing, dan Cause-Effect Relationship Testing (Safitri \& Pramudita, 2018). Berdasarkan penjelasan di atas, diterapkan salah satu teknik yaitu Boundary Value Analysis untuk menguji aplikasi penjualan berbasis web PT Karunia Segar Kedua. Cara yang dapat dilakukan untuk pengujian nilai yang dimasukkan ke dalam sistem antara lain:

a. Nilai harus dibuka/dibedah.

b. Dikelompokkan ke dalam batas yang dapat diidentifikasi.

c. Setiap set mengandung nilai yang diharapkan untuk diproses oleh komponen dengan cara yang sama.

d. Ketika merancang uji kasus sebaiknya memperhitungkan partisi yang valid dan tidak.

Pada penelitian $\mathrm{Xu}$ dkk dalam (Jaya,
2018), metode Black Box Testing salah satunya digunakan untuk menguji perangkat lunak sumber terbuka yaitu Advance Trigonometry Calculator dan Personal Bank Account Manager (YAPBAM). Hasil penelitian mengungkapkan bahwa:

- Dibutuhkan penerapan kombinasi semua perangkat lunak yang tersedia pada saat pengujian menyeluruh dan relatif akurat.

- Tingkat efisiensi pada teknik pengujian tertentu tidak menjamin jumlah bug yang akan ditemukan.

- Estimasi biaya perlu dilakukan pada saat analisa uji dengan penerapan setiap teknik pengujian.

- Apabila dalam uji kasus terdapat cacat maka dinyatakan dengan negatif.

- Revisi kesalahan tidak selalu dibutuhkan perubahan kode sumber.

\section{Rencana Pengujian}

Salah satu teknik Black Box Testing yang melakukan pengujian pada limit maksimal dan limit minimal nilai yang di isikan pada aplikasi disebut Boundary Value Analysis (Andriansyah, 2018). Dasar sejumlah teori yang ada pada Boundary Value Analysis (BVA) sebagai berikut (Mustaqbal, Firdaus, \& Rahmad, 2015):

1. Banyaknya kesalahan yang terjadi yaitu pada masukan.

2. Pengujian batasan nilai input diijinkan oleh BVA untuk menyeleksi pada uji kasus.

3. BVA lebih memilih elemen-elemen di dalam kelas ekivalen pada bagian sisi batas dari kelas. BVA merupakan pelengkap dari equivalence partitioning.

Aplikasi BVA dapat dilakukan secara generik dengan menjaga agar satu variable berada pada nilai nominal (normal atau rata-rata) dan mengijinkan variable lain dimasukkan dengan nilai maksimal. Nilai yang digunakan untuk menguji keekstriman data adalah Minimal, Minimal + 1, Rata-rata, Maksimum-1, dan Maksimum (Mustaqbal, Firdaus, \& Rahmad, 2015).

Berikut contoh yang akan di masukkan kode dengan deklarasi Alfanumerik, maka akan di dapatkan batas:

$$
0 \leq \operatorname{angka} \leq 9 \text { dan } \mathrm{A} \leq \text { huruf } \leq \mathrm{Z}
$$

Dalam penelitian tersebut, terdapat beberapa langkah yang dapat dilakukan yaitu mulai dari identifikasi masalah, pemilihan data 
uji, memasukkan data uji ke dalam sistem, proses pengujian dengan menggunakan Boundary Value Analysis, melakukan perhitungan data pengujian, sampai dengan dokumentasi hasil uji (Jaya, 2018). Adapun alur penelitian dan Form yang diuji dapat ditinjau pada Gambar.1 dan Gambar. 2.

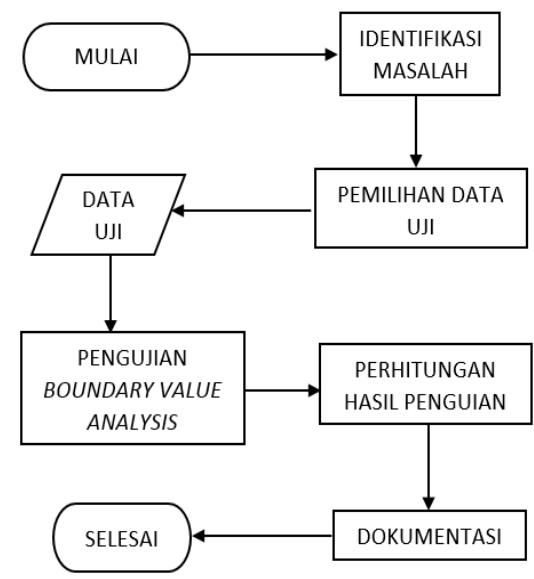

Gambar 1. Alur Penelitian

Alur penelitian sangat dibutuhkan oleh para penguji agar pengujian dapat berjalan secara terstruktur. Mulai adalah tahapan awal pada pengujian di mana penguji harus menentukan metode dan teknik apa yang akan digunakan. Pada pengujian ini menggunakan metode pengujian Black Box dengan teknik Boundary Value Analysis.

Tahap kedua adalah mengidentifikasikan masalah yang ada. Di sini masalah yang akan diuji yaitu validasi aplikasi yang tidak akurat di mana jumlah limit maksimum dan minimum tidak sesuai dengan data yang tersimpan pada basis data.

Tahap ketiga memilih data uji. Data uji yang akan digunakan yaitu data stok barang di mana data akan berkaitan dengan masalah yang ada.

Tahap keempat dan kelima yaitu menyiapkan data yang akan diuji kemudian melakukan pengujian dengan menggunakan pengujian Black Box berdasarkan teknik Boundary Value Analysis, yang nantinya akan menghasilkan sebuah kesimpulan untuk masalah yang ada.

Tahap keenam dan ketujuh yaitu menghitung hasil pengujian berdasarkan persentase yang dihasilkan pada saat pengujian dan kemudian melakukan dokumentasi untuk pelaporan pengujian.

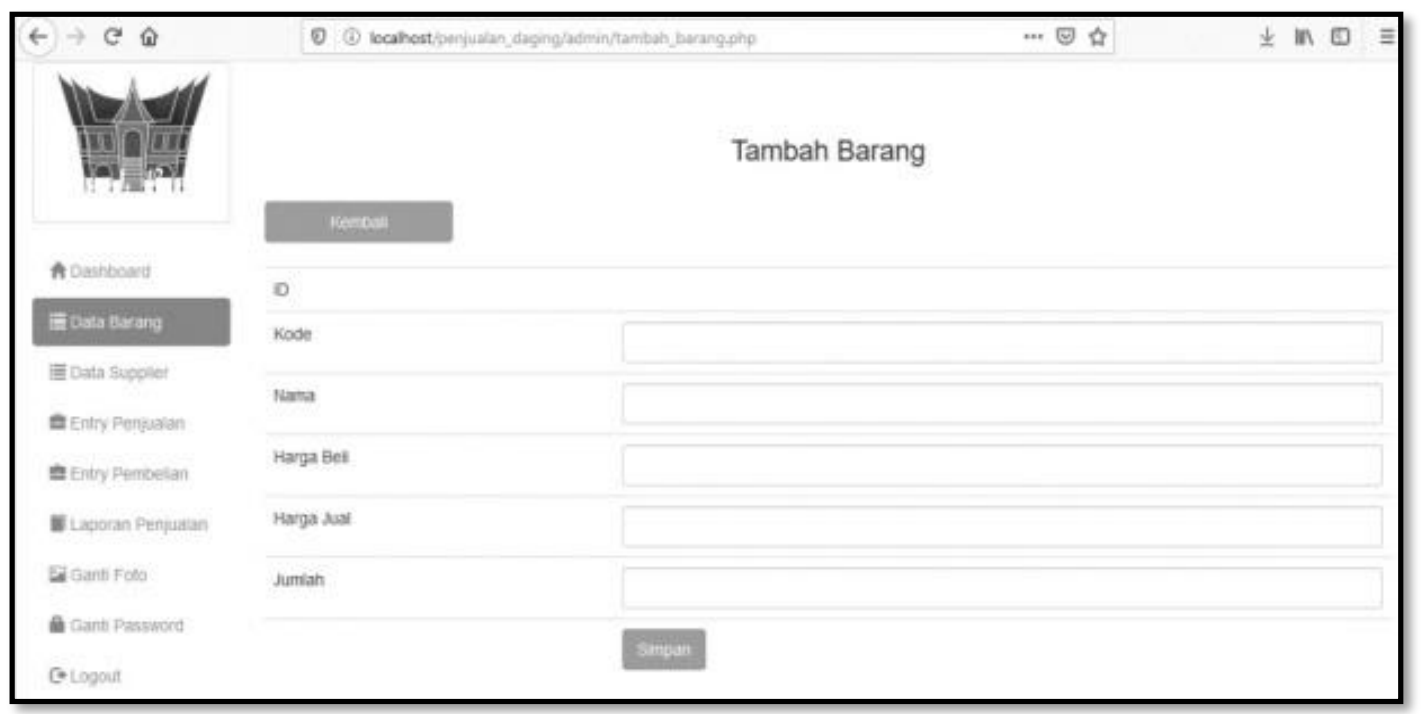

Gambar 2. Form Tambah Barang

Form diatas memiliki beberapa field yang harus diisi agar penambahan barang bisa dilakukan, yaitu: mengisi kode barang, nama barang, harga beli barang, harga jual barang, dan jumlah stok barang yang tersedia. Tombol SIMPAN berfungsi agar data yang sudah dimasukkan dapat tersimpan di database.

Untuk melakukan pengujian setiap field pada form di atas telah disiapkan beberapa skenario pengujian yang bertujuan untuk menangani berbagai macam input yang diberikan oleh pengguna. Khusus untuk field Kode tidak diujikan karena jenis elemen di dalam form merupakan autonumber, yang masukkannya sudah tersedia secara otomatis. Berdasarkan teknik BVA, didapatkan test case pengujian 
sebagai terikut:

Tabel 1.Tabel Test Case

\begin{tabular}{|c|c|c|c|}
\hline ID & Field yang diuji & Skenario pengujian & Hasil diharapkan \\
\hline \multirow[t]{3}{*}{1.} & Field Nama & $\begin{array}{l}\text { a. Memasukkan karakter } \\
\text { "Knuckle } 1 \mathrm{Kg} \text { " }\end{array}$ & a. Tidak ada pesan kesalahan \\
\hline & \multirow{2}{*}{$\begin{array}{l}\text { Ketentuan: } \\
\text { Field } \text { hanya dapat diisi } \\
\text { dengan } 20 \text { digit huruf, } \\
\text { angka, dan spasi }\end{array}$} & $\begin{array}{l}\text { b. Memasukkan karakter "Beef } \\
\text { \& } 4 \text { Kg" }\end{array}$ & $\begin{array}{l}\text { b. Karakter "\&" tidak dapat } \\
\text { dimasukkan }\end{array}$ \\
\hline & & $\begin{array}{l}\text { c. Memasukkan "Mutton Ribe } \\
\text { Eye } 1 \text { Kg John De" }\end{array}$ & $\begin{array}{l}\text { c. Terdengar bunyi beep setelah } \\
\text { memasukkan kata " } \mathrm{Kg} \text { " }\end{array}$ \\
\hline \multirow[t]{3}{*}{2.} & \multirow{3}{*}{$\begin{array}{l}\text { Field Harga Beli } \\
\text { Ketentuan: } \\
\text { Field hanya dapat diisi } \\
\text { angka maks } 6 \text { digit } \\
\end{array}$} & a. Memasukkan karakter "10" & a. Tidak ada pesan kesalahan \\
\hline & & $\begin{array}{l}\text { b. Memasukkan karakter } \\
\text { "1000000" }\end{array}$ & $\begin{array}{l}\text { b. Terdengar bunyi beep saat } \\
\text { memasukkan angka "0" yang ke } 6\end{array}$ \\
\hline & & c. Memasukkan karakter "-200" & $\begin{array}{l}\text { c. Karakter “_“" tidak dapat } \\
\text { dimasukkan. }\end{array}$ \\
\hline \multirow[t]{3}{*}{3.} & \multirow{3}{*}{$\begin{array}{l}\text { Field Harga Jual } \\
\text { Ketentuan: } \\
\text { Field hanya dapat diisi } \\
\text { angka maks } 6 \text { digit } \\
\end{array}$} & a. Memasukkan karakter "0" & a. Tidak ada pesan kesalahan \\
\hline & & $\begin{array}{l}\text { b. Memasukkan karakter } \\
\text { "100A" }\end{array}$ & $\begin{array}{l}\text { b. Karakter "A" tidak dapat } \\
\text { dimasukkan }\end{array}$ \\
\hline & & $\begin{array}{l}\text { c. Memasukkan karakter angka } \\
\text { "999999" }\end{array}$ & c. Tidak ada pesan kesalahan \\
\hline \multirow[t]{3}{*}{4.} & \multirow{3}{*}{$\begin{array}{l}\text { Field Jumlah } \\
\text { Ketentuan: } \\
\text { Field hanya dapat diisi } \\
\text { angka maks } 3 \text { digit. }\end{array}$} & $\begin{array}{l}\text { a. Memasukkan karakter angka } \\
\text { “9190" }\end{array}$ & a. Tidak ada pesan kesalahan \\
\hline & & b. Memasukkan karakter "A12" & b. Huruf "A" tidak dapat dimasukkan \\
\hline & & c. Memasukkan karakter "10 0" & $\begin{array}{l}\text { c. Pemberian spasi tidak dapat } \\
\text { dilakukan }\end{array}$ \\
\hline
\end{tabular}

\section{Hasil dan Pembahasan}

Aplikasi Penjualan Berbasis Web pada PT Karunia Segar Kedua mencakup beberapa fungsi dan modul, diantaranya penjualan, pembelian, pemasok, daftar barang, dan lain-lain. Tetapi pada pengujian ini diambil salah satu fungsi yaitu
“Tambah Barang" yang dinilai mampu mewakili fungsi-fungsi lain pada aplikasi tersebut.

Berdasarkan table test case pada pembahasan bab-bab sebelumnya, peneliti dapat menarik kesimpulan sebagai berikut:

Tabel 2. Hasil Pengujian

\begin{tabular}{|c|c|c|c|c|c|}
\hline ID & Field uji & Skenario pengujian & Hasil diharapkan & Hasil pengujian & Kesimpulan \\
\hline \multirow[t]{3}{*}{1.} & \multirow[t]{3}{*}{\begin{tabular}{|l} 
Field \\
Nama
\end{tabular}} & $\begin{array}{l}\text { Memasukkan karakter } \\
\text { "Knuckle } 1 \mathrm{Kg} \text { " }\end{array}$ & $\begin{array}{l}\text { - Tidak ada pesan } \\
\text { kesalahan }\end{array}$ & $\begin{array}{l}\text { Tidak ada pesan } \\
\text { kesalahan }\end{array}$ & Diterima \\
\hline & & $\begin{array}{l}\text { - Memasukkan karakter } \\
\text { "Beef \& } 4 \mathrm{Kg} "\end{array}$ & $\begin{array}{l}\text { - Karakter " } \& \text { " tidak } \\
\text { dapat dimasukkan }\end{array}$ & $\begin{array}{l}\text { - Karakter "\&" tidak } \\
\text { dapat dimasukkan }\end{array}$ & Diterima \\
\hline & & $\begin{array}{l}\text { Memasukkan "Mutton } \\
\text { Ribe Eye } 1 \text { Kg John De" }\end{array}$ & $\begin{array}{l}\text { - Terdengar bunyi } \\
\text { beep setelah karakter } \\
\text { "Kg" }\end{array}$ & $\begin{array}{l}\text { - Terdengar bunyi } \\
\text { beep setelah karakter } \\
\text { "Kg" }\end{array}$ & Diterima \\
\hline \multirow[t]{3}{*}{2.} & \multirow{3}{*}{\begin{tabular}{|l} 
Field \\
Harga \\
Beli
\end{tabular}} & $\begin{array}{l}\text { - Memasukkan karakter } \\
\text { "10" }\end{array}$ & $\begin{array}{l}\text { - Tidak ada pesan } \\
\text { kesalahan }\end{array}$ & $\begin{array}{l}\text { Tidak ada pesan } \\
\text { kesalahan }\end{array}$ & Diterima \\
\hline & & $\begin{array}{l}\text { Memasukkan karakter } \\
\text { "1000000" }\end{array}$ & $\begin{array}{l}\text { Terdengar beep saat } \\
\text { memasukkan angka "0" } \\
\text { yang ke } 6\end{array}$ & $\begin{array}{l}\text { - Terdengar beep saat } \\
\text { memasukkan angka ' } 0 \text { ' } \\
\text { yang ke } 6\end{array}$ & Diterima \\
\hline & & $\begin{array}{l}\text { Memasukkan karakter } \\
\text { "-200" }\end{array}$ & $\begin{array}{l}\text { - Karakter "_" tidak } \\
\text { dapat dimasukkan }\end{array}$ & $\begin{array}{l}\text { - Karakter "_“" tidak } \\
\text { dapat dimasukkan }\end{array}$ & Diterima \\
\hline \multirow[t]{2}{*}{3.} & \multirow{2}{*}{\begin{tabular}{|l} 
Field \\
Harga \\
Jual
\end{tabular}} & $\begin{array}{l}\text { - Memasukkan karakter } \\
\text { "0" }\end{array}$ & $\begin{array}{l}\text { - Tidak ada pesan } \\
\text { kesalahan }\end{array}$ & $\begin{array}{l}\text { - Tidak ada pesan } \\
\text { kesalahan }\end{array}$ & Diterima \\
\hline & & $\begin{array}{l}\text { Memasukkan karakter } \\
\text { "100A" }\end{array}$ & $\begin{array}{l}\text { - Karakter "A" tidak } \\
\text { dapat dimasukkan }\end{array}$ & $\begin{array}{l}\text { Karakter "A" tidak } \\
\text { dapat dimasukkan }\end{array}$ & Diterima \\
\hline
\end{tabular}




\begin{tabular}{|c|c|c|c|c|c|}
\hline & & $\begin{array}{l}\text { - Memasukkan karakter } \\
\text { angka "999999" }\end{array}$ & $\begin{array}{l}\text { - Tidak ada pesan } \\
\text { kesalahan }\end{array}$ & $\begin{array}{l}\text { - Tidak ada pesan } \\
\text { kesalahan }\end{array}$ & Diterima \\
\hline \multirow[t]{3}{*}{4.} & \multirow[t]{3}{*}{$\begin{array}{l}\text { Field } \\
\text { Jumlah }\end{array}$} & $\begin{array}{l}\text { - Memasukkan karakter } \\
\text { angka "9190" }\end{array}$ & $\begin{array}{l}\text { - Tidak ada pesan } \\
\text { kesalahan }\end{array}$ & $\begin{array}{l}\text { - Tidak ada pesan } \\
\text { kesalahan }\end{array}$ & Diterima \\
\hline & & $\begin{array}{l}\text { Memasukkan karakter } \\
\text { "A12" }\end{array}$ & $\begin{array}{l}\text { - Huruf "A" tidak } \\
\text { dapat dimasukkan }\end{array}$ & $\begin{array}{l}\text { - Huruf "A" tidak } \\
\text { dapat dimasukkan }\end{array}$ & ima \\
\hline & & $\begin{array}{l}\text { - Memasukkan karakter } \\
\text { "10 0" }\end{array}$ & $\begin{array}{l}\text { Pemberian spasi } \\
\text { tidak dapat dilakukan }\end{array}$ & $\begin{array}{l}\text { Pemberian spasi } \\
\text { tidak dapat dilakukan }\end{array}$ & Diterima \\
\hline
\end{tabular}

\section{Kesimpulan} poin, yaitu :

Pengujian di atas dapat diambil beberapa

1. Teknik pengujian Blackbox Testing Boundary Value Analysis adalah teknik pengujian yang relevan untuk diterapkan pada Aplikasi Penjualan Berbasis Web di PT Karunia Segar Kedua dengan menentukan jumlah limit minimum dan limit maksimum dari struktur data yang telah dirancang.

2. Dokumentasi hasil pengujian lebih mudah untuk diamati.

3. Hasil pengujian untuk fungsionalitas Form Tambah Barang adalah sukses 100\%.

Dari kesimpulan yang dapat diambil tersebut maka Aplikasi Penjualan Berbasis Web pada PT. Karunia Segar Kedua yang telah diuji dapat berjalan dengan baik sesuai dengan yang diharapkan dan di inginkan oleh pengguna, baik itu dari sisi fungsionalitas form maupun database. Validasi dapat dilakukan dengan aman tanpa khawatir akan adanya kesalahan.

\section{Saran}

Penerapan teknik pengujian black box yang berbeda seperti: equivalency partitioning dan test case dapat dilakukan untuk melanjutkan pengujian pada form yang lainnya.

\section{Referensi}

Andriansyah, D. (2018). Pengujian Kotak Hitam Boundary Value Analysis Pada Sistem Informasi Manajemen Konseling Tugas Akhir. Indonesian Journal on Networking and Security Vol 7 No 1, 13-18.

Cholifah, W. N., Yulianingsih, \& Sagita, S. M. (2018). Pengujian Black Box Testing pada Aplikasi Action \& Strategy Berbasis Android dengan Teknologi Phonegap. Jurnal String Vol 3 No 2, 206-210.
Hidayat, T., \& Muttaqin, M. (2018). Pengujian Sistem Informasi Pendaftaran dan Pembayaran Wisuda Online menggunakan Black Box Testing dengan Metode Equivalence Partitioning dan Boundary Value Analysis. Jurnal Teknik Informatika UNIS (JUTIS) Vol 6 No 1, 25-29.

Hidayat, T., \& Putri, H. D. (2019). Pengujian Portal Mahasiswa pada Sistem Informasi Akademik (SINA) menggunakan Black Box Testing dengan Metode Equivalence Partitioning dan Boundary Value Analysis. JUTIS Vol 7 No 1, 83-92.

Jaya, T. S. (2018). Pengujian Aplikasi dengan Metode Blackbox Testing Boundary Value Analysis (Studi Kasus: Kantor Digital Politeknik Negeri Lampung). Jurnal Informatika: Jurnal Pengembangan IT (JPIT) Vol 3 No 2, 45-48.

Mustaqbal, M. S., Firdaus, R. F., \& Rahmad, H. (2015). Pengujian Aplikasi Menggunakan Black Box Testing Boundary Value Analysis (Studi Kasus : Aplikasi Prediksi Kelulusan SNMPTN). Jurnal Ilmiah Teknologi Informasi Terapan Vol 1 No 3, 31-36.

MZ, M. K. (2016). Pengujian Perangkat Lunak Metode Black-Box Berbasis Equivalence Partitions pada Aplikasi Sistem Informasi Sekolah. Jurnal Mikrotik Vol 06 No 03, 1-18.

Safitri, N., \& Pramudita, R. (2018). Pengujian Black Box Menggunakan Metode Cause Effect Relationship Testing. Information System For Educators And Professionals Vol 3 No 1, 101-110.

Sutanto, Y., Utomo, A., \& Perbawa, D. S. (2018). Pengujian Aplikasi Website Menggunakan Black Box Testing Boundary Value Analysis (Studi Kasus : Aplikasi website praktekdokter). Jurnal SAINSTECH Politeknik Indonusa Surakarta Vol 5 No 2, 52-57.

Vikasari, C. (2018). Pengujian Sistem Informasi Magang Industri dengan Metode Blackbox Testing Boundary Value Analysis. SYNTAX Jurnal Informatika Vol 7 No 1, 44-51. 